\title{
The Sandwich Generation in Israel- Information Needs and Benefit Awareness
}

\author{
Dan Bouhnik', Yahel Giat ${ }^{2 *}$ \\ ${ }^{1}$ Department of Computers Sciences, Jerusalem College of Technology, Jerusalem, Israel \\ ${ }^{2}$ Department of Industrial Engineering and Management, Jerusalem College of Technology, Jerusalem, Israel \\ Email: ${ }^{*}$ yahel@g.jct.ac.il
}

Received 16 April 2014; revised 20 May 2014; accepted 19 June 2014

Copyright ( 2014 by authors and Scientific Research Publishing Inc.

This work is licensed under the Creative Commons Attribution International License (CC BY). http://creativecommons.org/licenses/by/4.0/

(c) $\underset{\mathrm{EY}}{\mathrm{E}}$ Open Access

\begin{abstract}
Members of the "sandwich generation" are people in the unique position of providing care both to their aging parents and their own children. In this research we examine the benefit awareness and the information needs of the sandwich generation in Israel with respect to the care it provides to its parents. Participants of this research were administered with a questionnaire whose results will be reported in this paper. We find that the sandwich generation's awareness of its rights is limited, suggesting a low utilization of rights and benefits. Our examination of the information needs reveals that the sandwich generation prefers traditional means of receiving information (such as traditional mail and booklets) in contrast to the modern information media (such as email and internet websites). These results imply that despite the digital revolution, social and welfare programs should not stop providing information in traditional manners.
\end{abstract}

\section{Keywords}

Ageing, Benefit Awareness, Digital Divide, Information Needs, Israel, Sandwich Generation

\section{Introduction}

As people grow older their needs change; it is the result of regression in their abilities and income. Consequently, the elderly are growing more dependent on various societal elements and must rely on outside assistance to overcome their disabilities and income problems. To overcome these difficulties the elderly must rely on a social network whose closest members are spouse and children. Children of the elderly_already caring for their own progeny — find themselves "sandwiched" between simultaneous care of parent and child. The term "sandwich generation" was therefore coined to describe the generation whose position requires it to provide care to both its

\footnotetext{
*Corresponding author.
} 
ageing parents and adult children (Schwartz, 1979; Chisholm, 1999).

Providing "upstream" and "downstream" care is a heavy burden on the sandwich generation that consequently experiences stress, anxiety, depression and other health problems (Riley \& Bowen, 2005). Information is an important tool to alleviate this burden by providing the sandwich generation access to caregivers, knowledge of their parents' rights, and so forth (Baruchson-Arbib, 1996).

In this paper we present quantitative research that examines two information-related aspects of the sandwich generation as its parents' primary caregiver. First, we investigate whether the sandwich generation is aware of the benefits and services that exist to serve its parents. This is achieved by testing whether the research participants are able to identify services that their parents are entitled to receive. Additionally, we examine whether participants are able to distinguish between fictitious benefits and existing benefits.

The second and more central research question aims to describe the characteristics of the information needs of the sandwich generation. In order to examine this we follow the Nicholas and Herman (2009) framework for information needs. This framework forms a comprehensive assessment of information needs by considering both the characteristics of the information consumers and the characteristics of the information required by these consumers.

We find that the sandwich generation is not knowledgeable about its rights in two aspects: first, it is unaware of rights and services to which it is entitled; second, it sometimes mistakenly believes that it is entitled to rights that do not exist.

We also find that as of today, the sandwich generation has not fully accepted the digital revolution and prefers to receive information in more traditional means. This result presents itself in a number of dimensions.

- Participants prefer to receive information from friends or personal contacts instead of obtaining it from the internet.

- Participants prefer receiving information in a booklet format rather than receiving it on a website.

- Participants prefer traditional mail to the e-mail.

The results of our research can be used by social services and NGOs to design better services to the sandwich generation, addressing this group’s specific information needs.

\section{Literature Review}

The discussion about information needs was initiated in Taylor's (1962) seminal paper discussing how one goes about asking for information. Other early research in this field includes Menzel (1966) and Paisley (1968) and a review by Wilson (1981). Nicholas (2000) and Nicholas and Herman (2009) have recently developed a framework for the assessment of information needs. This framework is comprised of the following two components, the demographic characteristics of the information seekers and the evaluation of the information that is needed.

1) Characteristics of the information consumers. This component includes demographic characteristics of the information consumers as well as personal characteristics.

2) The evaluation of the information needs includes the following aspects:

a) The required subject; its scope, nature, complexity and so forth.

b) The purpose for which this information is needed.

c) The description of the information; its sources, relevance and reliability.

d) The format of the delivery of the information.

Baruchson-Arbib (2007) describes the social and ethical effects of information. Our paper continues this line of research into how information is used to positively affect various social groups. Such research includes Bouhnik (2007) who focuses on the information needs of battered women, Shoham and Kauffman Strauss (2007) who treat the needs of English speaking immigrants in Israel, Woelfer and Hendry (2009) who focus on underserved populations and Lee and Trace (2009) who focus on hobbyist collectors.

Wiseman (2005) utilizes Nicholas' (2000) framework to investigate the information needs of the elderly population in Israel. She finds that the elderly are unaware of their rights and that they prefer traditional means of communication (media and mail to home) rather than the modern outlets (such as the internet and email). In addition, the elderly prefer to receive the information services at places they frequent such as old-age clubs and the HMO centers. In contrast to Wiseman (2005), which addresses information needs of the elderly, our research is concerned with the information needs of their children - the sandwich generation - whose information needs may differ from those of their parents. More precisely, we focus on the information needs of the sandwich generation with respect to their treatment of their parents. 
The trends and implications of population aging are extensively researched (see NIA (2007) for a global perspective). Even as governments are increasing the services to the elderly age group, assistance to this group is mostly provided by family members, notably the spouse. When the spouse is either deceased or unable to provide this help then the children are the most common source of care (Conway-Giustra et al., 2002; Wolkow, 1989, 2002).

Within the sandwich generation, most of the burden of support rests on the daughters (Wolkow, 2002). However, in recent years the participation of men providing care to their parents has risen from $26 \%$ to $31 \%$ (Center on an Aging Society, 2005). This increase comes as a result of women working more time outside the house, the increase in men's life expectancy and the change in family structures (Conway-Giustra et al., 2002; Wolkow, 1989, 2002).

Golan (1986) describes two models in which the sandwich generation functions when caring for its parents. The first is the care-manager, where the child manages the care of his parent by having others provide the care directly. The second model is as a care-provider, where the child handles most of the care independently. The differences between the models may lead to different information needs. For example, the care-manager needs information about social solutions for her/his parents, whereas the care-provider needs information on how to provide the care-giving her/himself.

Ruthven et al. (2003) and Gwizdka and Lopatovska (2009) find that even subjective factors affect the success of information search. Accordingly, caregivers who are under the stress of treating their parents and children such as the sandwich generation may find this task of searching much more difficult.

There is abundant research about the use of internet as a source of information towards improving quality of life. However, the use and accessibility to the internet decreases with age (Jones \& Fox, 2009; National Statistics, 2006), and therefore, while the sandwich generation is more digitally-literate than its parents, it is still not as comfortable with its use as the younger generation. Hill et al. (2008) examine participants of a UK public program for introducing people to the internet, the majority of whom belong to the sandwich generation and older. In their paper, they develop a model for internet engagement, and find that the participants' engagement with the internet is inconsistent and depends on the specific tools and purposes. It is therefore unclear whether modern information tools (such as the internet) are the most significant sources of information for the sandwich generation in providing and managing its parents' care.

\section{Research Questions}

It is well documented by researchers that many groups are not fully aware of their rights (Stafford, 2003; Hernanz et al., 2004; Walker, 2005). Specifically for Israel, Gal (2007) claims that there is very little research about the take up of social benefits in Israel, and the little which exists indicates that the take-up of the benefits is apparently low. Moreover, individuals in need of information are frequently unaware of such a need. This "hidden" information, denoted by Nicholas and Herman (2009) as "dormant information," is occasionally revealed when the individual is searching for other information. In light of the research about the low benefit awareness of various social groups, we wish to examine the degree of benefit awareness of the sandwich generation. Accordingly, the first research question is:

Research Question 1: To what extent is the sandwich generation aware of the rights and services that exist to serve its parents?

Information needs have various dimensions (Nicholas \& Herman, 2009). In the second research question we examine six such dimensions:

1) Information providers: This dimension describes the possible sources of information for the information seekers. Such sources can be official (such as professional experts and Social Security consultants) or unofficial (such as friends; neighbors; media and children).

2) Subject: This dimension describes needs that are known to both the information seekers and the information professionals (Shenton, 2007) and includes all information topics sought by information consumers.

3) Writing Style: The style in which the information is presented affects the ability of the information seekers to understand and take better advantage of the information. This writing style can range between day to day summary of the benefits to professional and precise quotations of the law.

4) Information Medium: This dimension is the means by which the information arrives to the seeker. This could be through traditional means (hand delivery at home or in public locations) or modern means (email). 
5) Format: The format or packaging of the information is another dimension that we examine.

6) Information location: The accessibility of the information is of high importance to information seekers. For example, research demonstrates that people remain unable to sort and retrieve relevant information in spite of the digital revolution and the availability of information on the internet. In addition, there is still the issue of digital illiteracy, which may hinder people from accessing digital information (Jones \& Fox, 2009).

There is also research evidence about the demographic effects on the information needs. For example, National Statistics (2006) finds that high-income households are more digital literate than low-income households. It also finds that men use the internet more frequently than women.

We include these issues within the second research question as follows:

Research Question 2: What are the characteristics of the information needs of the sandwich generation (with respect to their parents)?

\section{Methodology}

\subsection{Tools}

A quantitative research methodology is employed in this study. Data is gathered through a questionnaire administered to participants in person. This questionnaire is based on Wiseman (2005).

The first 10 questions examine the demographic characteristics of the participants. Question 11 asks for the participants activities in their free time and Question 12 examines the ability level of the participants' parents. Questions 13 - 14 examine the willingness of participants to accept advice from others and their desire for discretion.

Question 15 addresses the first research question. In this question we examine participants' knowledge of their rights.

In Questions 16 - 23 we address the second research question by examining the following six dimensions, which are at the core of the framework for information needs Nicholas and Herman (2009):

- Information providers (Question 16, Question 21): In Question 16, we ask the participants to indicate their preferred information source. These sources included: Friends; Neighbors; Media; Children and Grandchildren; Professional Experts; Social Security Consultants; Local SIL Branch; Internet; Information Center Reut-Eshel and Other. In Question 21 we ask the participants to indicate how important it is to have a person whose job is to provide them information.

- Subject (Question 17): We ask participants the degree to which they want information on the following topics: Property Tax Discounts, Social Security Benefits, Legal Counseling about Wills and Inheritance Laws, Places where Information Services can be Found, Holocaust Survivors Benefits, Funding for Old Age Homes, Leisure Services, HMO services, Others.

- Writing Style (Question 19b): We ask participants about their preferred writing style ranging between day to day summary style and the precise quotations of the law.

- Information Medium (Question 22): We ask participants about their preferred medium amongst Telephone, Face to Face Meeting with the Information Provider, Fax, Post Mail, Distribution in Public Locations (e.g. HMO/Local Library), Delivery to Home by a Volunteer, Email, Others.

- Format (Question 23 a-d): We ask participants about their preferred format amongst Booklets; Tapes/CD’s; Website; Others.

- Information location (Question 23 e-g): We ask participants to indicate the preferred location for receiving information about their rights. The options included in this question are: Public Library/Culture Center, City Hall, HMO Center, Others.

\subsection{Population of Study}

The participants of this research are adult students who study in the Bar-Ilan University Brookdale Program. This program includes enrichment and academic courses offered by the university. Participant age ranges between 40 and 60 and all participants have at least one living parent. 146 questionnaires were fully completed. Tables 1-3 describe the characteristics of the participants. In Table 1 we summarize demographic characteristics, Table 2 describes the free time activities of the participants and in Table 3 we describe the disability levels of the participants' parents. 
Table 1. Population study characteristics.

\begin{tabular}{cccc}
\hline & Characteristic & N & $\%$ \\
\hline \multirow{2}{*}{ Gender (Q4) } & Male & 35 & 24.0 \\
& Female & 111 & 76.0 \\
Age Group & $41-45$ & 17 & 11.6 \\
& $46-50$ & 21 & 14.4 \\
Marital Status & $51-55$ & 50 & 34.2 \\
& $56-60$ & 58 & 39.7 \\
With Children & Married & 122 & 83.6 \\
& Unmarried & 24 & 16.4 \\
With Grandchildren & Yes & 139 & 95.2 \\
& No & 7 & 4.8 \\
Academic Education & Yes & 83 & 56.8 \\
& No & 63 & 43.2 \\
\hline \multirow{2}{*}{ Economic Status } & Yes & 89 & 61 \\
& No & 57 & 39 \\
& High & 79 & 54.1 \\
& No Medium & 67 & 45.9 \\
\hline
\end{tabular}

Table 2. Free time activities of participants.

\begin{tabular}{ccc} 
Activity & N & $\%$ \\
Volunteer work & 73 & 50 \\
Care of Parents & 52 & 36 \\
Care of spouse's parent & 27 & 8 \\
Religious activities & 11 & 22 \\
Work for wage & 32 & 75 \\
Participation in courses & 109 & 1 \\
Political Party & 2 & 31 \\
Others & 45 & \\
\hline
\end{tabular}

Table 3. Disability levels of participants’ parents.

\begin{tabular}{cccc}
\hline Disability type & No Disability & Partial Disability & Full Disability \\
\hline Mobility & $\mathrm{N}=61(41.8 \%)$ & $\mathrm{N}=62(42.5 \%)$ & $\mathrm{N}=23(15.8 \%)$ \\
Sight & $\mathrm{N}=95(65.1 \%)$ & $\mathrm{N}=47(32.2 \%)$ & $\mathrm{N}=4(2.7 \%)$ \\
Hearing & $\mathrm{N}=97(66.4 \%)$ & $\mathrm{N}=43(29.5 \%)$ & $\mathrm{N}=6(4.1 \%)$ \\
\hline
\end{tabular}

We include in this research also the participants without children for two reasons. First, these participants belong to the same age group of the members of the sandwich generation. While they do not share the burden of carrying for their children, they do share the burden of carrying for their parents, which is the focus of this 
research. Second, as expected from this group age and the Israeli demographics, the number of participants who have no children is less than $5 \%$ of the sample. We examine the results absent these participants and they do not differ significantly.

\subsection{Research Limitations}

Participants of this research are drawn from a very specific segment of the general population. Specifically, the participants of this research are relatively well educated, taking part in an enrichment study program affiliated with an academic institution. Additionally, there may be cultural effects associated with the fact that our participants belong to a Jewish group in Israel who are mostly religious. This, for example, may affect the results with respect to the use of the internet as a source of information due to the inclination of ultra-orthodox Jews to avoid the internet. Finally, the representation of women in the study sample is greater than that of women in the general population.

\section{Results}

\section{Results for Research Question 1:}

Participants are given 18 statements stating different services and rights for the elderly. Eight of these statements exist in Israeli law and the other ten are fictitious. The participants are asked to identify those rights that are indeed granted by Israeli law. The results of this question are given in Table 4.

We define the participant's knowledge of his/her rights as high if she/he answered more than $70 \%$ of the answers correctly, medium as between $40 \%$ and $69 \%$ and low as less than $40 \%$.

The number of correct answers for each participant $(M=5.79, S D=3.04)$ ranged between zero (five participants had not a single correct answer) and 15 . The relatively low number of correct answers demonstrates that members of the sandwich generation have a low awareness of benefits and rights.

We conduct t-tests with respect to the discrete demographic variables of the participants. The results are:

- Participants with grandchildren are more aware of their rights $(\mathrm{M}=6.24, \mathrm{SD}=3.01, \mathrm{n}=83)$ compared to participants without grandchildren $(\mathrm{M}=5.20, \mathrm{SD}=3.00, \mathrm{n}=63)$. This difference is significant $(\mathrm{t}(144)=$ 2.056, $p<0.05)$.

- Participants without academic education are more aware of their rights $(M=6.61, \mathrm{SD}=2.95, \mathrm{n}=57)$ compared to participants with academic education $(\mathrm{M}=5.27, \mathrm{SD}=2.99, \mathrm{n}=89)$. This difference is significant $(\mathrm{t}(144)=2.657, p<0.01)$.

The other demographic variables do not significantly affect participants' awareness of their parents' rights.

Pearson coefficients are computed between the knowledge of benefits and the continuous demographic variables. The Pearson coefficient between the degree of education and the knowledge of rights is negative and significant. ( $r=-0.232, \mathrm{R}^{2}=0.049, p \leq 0.05$ ). Surprisingly, we find that the knowledge of benefits decreases with the degree of education. There is no significant relationship between the knowledge and the other discrete variables.

\begin{tabular}{|c|c|c|c|}
\hline & The Statement & $\mathrm{N}^{\mathrm{a}}$ & $\%^{\mathrm{b}}$ \\
\hline 1 & $30 \%$ discount in residential property tax for senior citizens & 102 & $69.9 \%$ \\
\hline 2 & Free consulting services in Social Security on various issues & 69 & $47.3 \%$ \\
\hline 3 & $75 \%$ discount for prescription drugs, for senior citizens who are receiving income supplements & 52 & $35.6 \%$ \\
\hline 5 & Nursing benefits may be also used towards laundry services & 21 & $14.4 \%$ \\
\hline 8 & $100 \%$ discount in residential property tax for senior citizens receives income supplement & 37 & $25.3 \%$ \\
\hline 14 & $50 \%$ discounts in theatres for senior citizens & 90 & $61.6 \%$ \\
\hline 15 & Any senior citizen over the age of 80 is entitled to income supplement benefits & 12 & $8.2 \%$ \\
\hline 17 & Nursing benefits rate are $100 \%$ or $150 \%$ depending on the needs of the senior citizen & 26 & $17.8 \%$ \\
\hline
\end{tabular}

${ }^{\mathrm{a}} \mathrm{N}$ indicates the number of participants that answered correctly; ${ }^{\mathrm{b}} \%$ indicates the percent of sample size. 


\section{Results for Research Question 2:}

Information providers: We provide the participants with a list of common information providers. For each provider, the participants are asked to denote on a Likert scale of 1 - 5 their attitude towards the provider. Results are given in Table 5 .

Parity tests show that friends, media and professionals are significantly higher than all other sources of information except for the internet.

We conduct t-tests with respect to the discrete demographic variables of the participants. The results are:

- Men $(\mathrm{M}=3.77, \mathrm{SD}=1.31, \mathrm{n}=35)$ use the internet more than women $(\mathrm{M}=3.16, \mathrm{SD}=1.64, \mathrm{n}=111)$. This difference is significant $\mathrm{t}(144)=2.252, p<0.001$.

- Participants with higher socio-economical level $(\mathrm{M}=3.96, \mathrm{SD}=1.3, \mathrm{~N}=67)$ are assisted by friends more than participants who are of lower socio-economical level $(\mathrm{M}=3.49, \mathrm{SD}=1.41, \mathrm{~N}=79)$. This difference is significant $\mathrm{t}(144)=2.042, p<0.05$.

The participants are asked to what extent they want an information specialist to provide them with information about services that exist for their parents (Question 21 of the questionnaire). 95\% of participants expressed their desire for such service $(\mathrm{M}=4.34, \mathrm{SD}=1.16)$. The results to this answer are given in Table 6 .

Subject: We provide the participants with a list of information subjects. The participants are asked to denote on a Likert scale of 1 - 5 the degree to which they want information on each subject. Results are given in Table 7.

Table 5. Participants’ preferences about information providers.

\begin{tabular}{ccc}
\hline Statement & Mean (M) & SD \\
\hline Friends & 3.71 & 0.114 \\
Neighbors & 2.41 & 0.115 \\
Media & 3.66 & 0.111 \\
Children and Grandchildren & 3.07 & 0.124 \\
Professional Experts & 3.65 & 0.105 \\
SS consultants & 2.28 & 0.115 \\
local SIL branch & 1.67 & 0.101 \\
Internet & 3.31 & 0.131 \\
Information Center Reut-Eshel & 1.30 & 0.072 \\
Other & 1.24 & 0.070
\end{tabular}

Table 6. Participants' request for an information specialist.

\begin{tabular}{cccccc}
\hline Degree & 1 (High) & 2 & 3 & 4 & 5 (Low) \\
\hline $\mathrm{N}$ & 94 & 19 & 10 & 10 & 7 \\
$\%$ & $64.4 \%$ & $13.0 \%$ & $6.8 \%$ & $6.8 \%$ & $4.8 \%$ \\
\hline
\end{tabular}

Table 7. Preference levels for information subjects.

\begin{tabular}{ccc}
\hline Topic & M & SD \\
Property Tax Discounts & 4.41 & 1.19 \\
Social Security Benefits & 4.51 & 1.13 \\
Legal Counseling about Wills and Inheritance Laws & 3.79 & 1.54 \\
Places where Information Services can be Found & 4.41 & 1.19 \\
Holocaust Survivors Benefits & 2.54 & 1.83 \\
Funding for Old Age Homes & 3.71 & 1.70 \\
Leisure Services & 3.82 & 1.52 \\
HMO services & 4.24 & 1.30 \\
Others & 2.29 & 1.36 \\
\hline
\end{tabular}


A One Way ANOVA with Repeated Measures was conducted to test for differences in preferences of information topics. Results demonstrate significant differences in preference levels amongst various topics $\mathrm{F}(7,115)$ $=44.63, p<0.001$.

Parity tests reveal that Property Tax Benefits, SS benefits and Places where Information can be found are significantly higher than all other subjects of information except for HMO Services.

Information Writing Style: The participants are asked whether they want their information summarized in day-to-day language or prefer the entire version as written in the State law books.

The results reveal that almost all the participants (91.09\%) want to receive their legal rights summarized in a non-legal language style. The results to this answer $(\mathrm{M}=4.34, \mathrm{SD}=1.14)$ are given in Table 8 .

Information Medium: The participants are given a list of information media and are asked to denote on a Likert scale of 1 - 5 their attitudes to each of the media. The results to this question are given in Table 9.

Single Sided Variance Analysis with repetitive measurements reveals significant difference between preference levels of information media $\mathrm{F}(6,870)=18.41, p<0.001$. Parity tests show that receiving information by mail is significantly higher than all other information media. We do not find that email is significantly higher than Face to Face or Telephone. In addition, participants of higher socio-economic standing $(\mathrm{M}=4.12, \mathrm{SD}=$ $1.47, \mathrm{~N}=67$ ) prefer to receive information via email more than participants of lower socio-economic standing $(\mathrm{M}=3.23, \mathrm{SD}=1.86, \mathrm{~N}=79)$. This difference is significant $\mathrm{t}(144)=3.231, p<0.001$.

The Pearson coefficient between the degree of education and the willingness to receive information via email is positive and significant ( $\mathrm{rp}=0.261, p \leq 0.05)$. That is, we find that preferring email is positively tied with the socio-economic degree. There is no significant relationship between the various information mediums and the other discrete variables.

Information Format: The participants are given a list of information formats, i.e. the packaging of which the information is received. The participants are asked to denote on a Likert scale of 1 - 5 their attitudes about each format. The results are given in Table 10.

Single Sided Variance Analysis with repetitive measurements demonstrates significant differences in preferred information formats $F(2,290)=96.64, p<0.001$. Parity tests show that receiving information in Booklets was significantly higher than all other formats of information. Website is significantly higher than Tape/CD.

Participants with higher socio-economic level $(\mathrm{M}=4.19, \mathrm{SD}=1.40, \mathrm{~N}=67)$ prefer Website more than participants who are of lower socio-economical level $(\mathrm{M}=3.34, \mathrm{SD}=1.82, \mathrm{~N}=79)$. This difference is significant $\mathrm{t}(144)=3.149, p<0.001$.

Table 8. Preference for information writing style.

\begin{tabular}{cccccc}
\hline Writing Style $^{\mathrm{a}}$ & 1 & 2 & 3 & 4 & 5 \\
\hline $\mathrm{N}$ & 8 & 5 & 15 & 19 & 99 \\
$\%$ & $5.5 \%$ & $3.4 \%$ & $10.3 \%$ & $13.0 \%$ & $67.8 \%$ \\
\hline
\end{tabular}

${ }^{\text {a }}$ response 1 indicates full version of the law, response 5 indicates summary version of rights and services.

Table 9. Preference levels for information media.

\begin{tabular}{ccc}
\hline Medium & M SD \\
Telephone & 3.13 & 1.67 \\
Fax & 3.58 & 1.53 \\
Face to Face Meeting with the Information Provider. & 2.84 & 1.77 \\
By Post Mail & 4.10 & 1.70 \\
Distribution in Public Locations (e.g. HMO/Local Library) & 2.92 & 1.62 \\
Delivery to home by a volunteer & 2.68 & 1.75 \\
Ethers & 3.64 & 1.31 \\
\hline
\end{tabular}


Table 10. Preference levels for information format.

\begin{tabular}{cccc}
\hline Format & M & SD \\
\hline Booklets & 4.18 & 1.38 \\
Tapes/CD's & 2.10 & 1.50 \\
Website & 3.73 & 1.69 \\
Others & 1.14 & 1.26 \\
\hline
\end{tabular}

Male participants $(\mathrm{M}=4.29, \mathrm{SD}=1.30, \mathrm{~N}=35)$ prefer Website more than female participants $(\mathrm{M}=3.56$, SD $=1.77, \mathrm{~N}=111)$. This difference is significant $\mathrm{t}(144)=2.635, p<0.01$.

Information Location: The participants are given a list of locations in which the information may be provided. The participants are asked to denote on a Likert scale of 1 - 5 their attitudes about each location. The results are given in Table 11.

Single Sided Variance Analysis with repetitive measurements shows significant difference between location preferences, $\mathrm{F}(2,290)=40.60, p<0.001$. Parity tests reveal that the HMO location is more preferable than all other locations, and that City Hall is preferred more than the Public Library-both findings are significant.

Pearson Coefficients are computed to find the relationship between socio-economical level and the location preferences. We find significant negative relationship between socio-economical level and preference for City Hall $(\mathrm{rp}=-0.284, p<0.001)$ and the HMO ( $\mathrm{rp}=-0.227, p<0.05)$.

\section{Discussion}

We find that most participants are unaware of their rights. This is evident by the fact that the average participant answered correctly to less than one third of the statements (5.79 of 18) and that for all correct statements participants answered correctly less than $50 \%$. The only exception to this is the statement concerning discounts on property taxes, which the majority of the participants were able to identify correctly. This result is consistent with findings that people in general are unaware of their rights regarding services and benefits. We also find that people with academic education are less aware of these rights than those without an academic education.

This result seemingly contrasts Gal (2007) who claims that education level positively affects the take up of benefits. A possible explanation to this contradiction is that the benefits for the sandwich generation with respect to their parents in Israel have a relatively low monetary value and therefore it is possible that people with academic background are less motivated to learn and pursue those rights. In the digital era we expect to find the internet as a valuable resource for information. Surprisingly, our research reveals that traditional mail is still the preferred medium for information with email only taking the second place. Similarly, we find that friends are the most preferred information providers, followed by media, professionals and then the internet. The importance of friends as information providers is similar to Moffit (2003) who finds that tighter social networks increase benefit take up.

The fact that the internet is not such an important source of information and that email is not the most preferred medium for information may have a number of reasons. First, members of the sandwich generation are between the ages of 40 - 65, they may be less digitally literate than younger generations as found in previous research and surveys (Jones \& Fox, 2009; National Statistics, 2006). Second, the information of government websites in Israel is not as developed as in the US-many of the services can be rendered only in person in the government offices - and therefore people do not see the internet as the ultimate source for acquiring benefits or information about these benefits. Participants are consistent in their preference of traditional means for information. Thus, preferring friends over the internet as a source of information is complemented by the preference of booklets to any other format of information.

Our results show gaps between different groups with respect to internet and email usage as follows:

Gender: We find that men prefer the internet more than women. For example, men's attitudes towards websites as a format of information are more positive than women's. This result reaffirms the findings that men in Israel are more digitally literate than women. This is similar to empirical results that find that in Israel men are more frequent internet users than women (Enoch \& Soker, 2006). This finding contrasts studies in the US that show no gender-based digital divide (Wilson et al., 2003). 
Table 11. Preference levels for information location.

\begin{tabular}{ccc}
\hline Location & M & SD \\
\hline Public Library/Community Centre & 1.96 & 1.36 \\
City Hall & 2.25 & 1.59 \\
HMO & 3.01 & 1.76 \\
\hline
\end{tabular}

Level of education and income level: We find that internet preference increases with income and education level. These results support research about the "digital divide" between low and high income households as well as between less and more educated individuals (Martin \& Robinson, 2007). We anticipate that these results are likely to change in the coming years as the younger, more digital literate population, becomes the new sandwich generation.

Our results show that the subjects of the information needs are more related to monetary issues rather than services and that the writing style of this information has to be balanced between simple day-to-day and lawstyle writing.

The HMO center is the preferred location for receiving information. We believe this stems from the frequent visits to the HMO made by this age group, which cares for themselves and family members and therefore find the HMO to be an accessible and therefore preferable location.

The results of this research can be used by government agencies and NGOs in various ways when assisting the sandwich generation to support their elderly parents. First and foremost, the focus of these agencies should be on providing information in more traditional routes rather than shifting the focus to the modern, digital era channels. Second, the sandwich generation is clearly unaware of the services provided by these agencies and more must be done to increase the awareness and take up of these services and benefits. Finally, there are differences in attitudes between various groups within the sandwich generation-gender, income level and education level. The information needs of these groups vary and service providers should make the effort to tailor their services according to these varying needs.

\section{Concluding Remarks}

In this research we address the information needs of the sandwich generation and examine how well members of this group are aware of their rights and benefits with respect to provision of care to their parents. The sandwich generation is a very unique population in the way that it provides both "upstream" and "downstream" care. Therefore, optimally addressing its information needs will positively affect not only the sandwich generation but also the groups that depend on it for care.

In this work we find that the sandwich generation has poor awareness of its rights. We characterize their information needs, and we find that they prefer traditional information providers, locations, and information media. Since digital literacy is increasing over time, it is anticipated that future members of the sandwich generations will prefer the more modern sources, formats and locations of information. In the meantime, however, it is important that information and service providers to the sandwich generation emphasize traditional means rather than the modern means of information.

\section{Acknowledgements}

We thank Snir Kenyas for collecting the data for this research.

\section{References}

Baruchson-Arbib, S. (1996). Social Information Science: Love, Health and Information Society. Brighton: Sussex Academic Press,.

Baruchson-Arbib, S. (2007). The Contribution of "Information Science" to the Social and Ethical Challenges of the Information Age. Journal of Information, Communication and Ethics in Society, 5, 53-58. http://dx.doi.org/10.1108/14779960710837560

Bouhnik, D. (2007). A Model Design Proposal of a Supportive Web Site for Women Experiencing IPV: Catering for Needs at Different Phases of the Coping Process. Journal of Information, Communication and Ethics in Society, 5, 116-139.

http://dx.doi.org/10.1108/14779960710837605 
Chisholm, J. F. (1999). The Sandwich Generation. Journal of Social Distress and the Homeless, 8, 177-191. http://dx.doi.org/10.1023/A:1021368826791

Center on an Aging Society (2005). A Decade of Informal Caregiving. Family Caregivers of Older Persons, 1. http://hpi.georgetown.edu/agingsociety/pubhtml/caregiver1/caregiver1.html

Conway-Giustra, F., Crowley, A., and Gorin, S. H. (2002). Crisis in Caregiving: A Call to Action. Health and Social Work, 27, 307-311. http://dx.doi.org/10.1093/hsw/27.4.307

Enoch, Y., \& Soker, Z. (2006). Age, Gender, Ethnicity and the Digital Divide: University Students' Use of Web Based Instruction. Open Learning, 21, 99-110. http://dx.doi.org/10.1080/02680510600713045

Gal, J. (2007). On the Importance of Utilizing Rights. Social Security, 73, 5-9.

Golan, N. (1986). The Perilous Bridge: Helping Clients through Mid-Life Transitions. New York: Free Press.

Gwizdka, J., \& Lopatovska, I. (2009). The Role of Subjective Factors in the Information Search Process. Journal of the American Society for Information Science and Technology, 60, 2452-2464. http://dx.doi.org/10.1002/asi.21183

Hernanz, V., Malherbet, F., \& Pellizzari, M. (2004). Take-Up of Welfare Benefits in OECD Countries: A Review of the Evidence. OECD Social Employment and Migration Working Papers, No. 17, Paris: OECD Publishing.

Hill, R., Beynon-Davies, P., \& Williams, M. D. (2008). Older People and Internet Engagement: Acknowledging Social Moderators of Internet Adoption, Access and Use. Information Technology \& People, 21, 244-266. http://dx.doi.org/10.1108/09593840810896019

Jones, S., \& Fox, S. (2009). Generations Online in 2009. Pew Research Center http://www.pewinternet.org/Reports/2009/Generations-Online-in-2009.aspx

Lee, C. P., \& Trace, C. B. (2009). The Role of Information in a Community of Hobbyist Collectors. Journal of the American Society for Information Science and Technology, 60, 621-637. http://dx.doi.org/10.1002/asi.20996

Martin, S. P., \& Robinson, J. P. (2007). The Income Digital Divide: Trends and Predictions for Levels of Internet Use. Social Problems, 54, 1-22. http://dx.doi.org/10.1525/sp.2007.54.1.1

Menzel, H. (1966). Information Needs and Uses in Science and Technology. Annual Review of Information Science and Technology, 1, 41-69.

Moffit, R. (2003). The Role of Non-Financial Factors in Exit and Entry in the TANF Program. Journal of Human Resources, 38, 1221-1254. http://dx.doi.org/10.2307/3558986

National Statistics (2006). Internet Access Households and Individuals. (Accessed May 1, 2010) http://www.statistics.gov.uk/pdfdir/inta0806.pdf

NIA (National Institute on Aging) (2007). Why Population Aging Matters: A Global Perspective. Report by the National Institute on Aging, Summit on Global Aging. (Accessed March 2, 2010)

http://www.nia.nih.gov/ResearchInf ormation/ExtramuralPrograms/BehavioralAndSocialResearch/GlobalAging.htm

Nicholas, D. (2000). Assessing Information Needs: Tools, Techniques and Concepts for the Internet Age. London: ASLIB.

Nicholas, D., \& Herman, E. (2009). Assessing Information Needs in the Age of the Digital Consumer. New York: Routledge.

Paisley, W. J. (1968). Information Needs and Uses. Annual Review of Information Science and Technology, 3, 1-30.

Riley, L. D., \& Bowen, C. P. (2005). The Sandwich Generation: Challenges and Coping Strategies of Multigenerational Families. The Family Journal: Counseling and Therapy for Couples and Families, 13, 52-58. http://dx.doi.org/10.1177/1066480704270099

Ruthven, I., Mounia, L., \& van Rijsbergen, K. (2003). Incorporating User Search Behavior into Relevance Feedback. Journal of the American Society for Information Science and Technology, 54, 529-549. http://dx.doi.org/10.1002/asi.10240

Schwartz, A. N. (1979). Psychological Dependency: An Emphasis on the Later Years. In P. K. Ragan (Ed.), Aging Parents (pp. 116-125). Los Angeles: Andrus Gerontology Center, University of South California.

Shenton, A. K. (2007). Viewing Information Needs through a Johari Window. Reference Services Review, 35, 487-496. http://dx.doi.org/10.1108/00907320710774337

Shoham, S., \& Kaufman Strauss, S. (2007). Information Needs of North American Immigrants to Israel. Journal of Information, Communication and Ethics in Society, 5, 185-205. http://dx.doi.org/10.1108/14779960710837641

Stafford, B. (2003). Service Delivery and the User. In J. Millar (Ed.), Understanding Social Security (pp. 213-234). Bristol: Policy Press.

Taylor, R. S. (1962). Process of Asking Questions. American Documentation, 13, 391-396. http://dx.doi.org/10.1002/asi.5090130405

Walker, R. (2005). Social Security and Welfare. Maidenhead: Open University Press. 
Wilson, T. D. (1981). On User Studies and Information Needs. Journal of Documentation, 37, 3-15. http://dx.doi.org/10.1108/eb026702

Wilson, K. R., Wallin, J. S., \& Reiser, C. (2003). Social Stratification and the Digital Divide. Social Science Computer Review, 21, 133-143. http://dx.doi.org/10.1177/0894439303021002001

Wiseman, G. (2005). Information Needs of People Sixty Years and Older. Master Thesis, Ramat Gan: Bar-Ilan University.

Woelfer, J. P., \& Hendry, D. G. (2009). Stabilizing Homeless Young People with Information and Place. Journal of the American Society for Information Science and Technology, 60, 2300-2312. http://dx.doi.org/10.1002/asi.21146

Wolkow, L. (1989). To Be a Child of an Aging Person. Tel Aviv: Poalim Library Press.

Wolkow, L. (2002). The Increase in Life-Expectancy and Its Effects on the Sandwich Generation: How Does It Affect Me? Family and Knowledge, 2, 54-57. 


\section{Appendix-Questionnaire}

I would appreciate if you could spend a few minutes to complete this questionnaire.

The questionnaire is anonymous. Your answers will not be given to anyone else, and will be used for research purposes only.

Thank you for participating in the study.

1. Country of birth:

2. Year of Aliya:

3. City of residence:

4. Gender (please circle): a. male b. female

5. Age:

6. Marital status: a. single b. married c. divorced

d. widow e. living with a partner

7. Do you have children? a. yes b. no

8. Do you have grandchildren? a. yes b. no

9. Education: a. none b. elementary school c. high school

d. academic e. yeshiva f. other

10. How would you define your financial status?

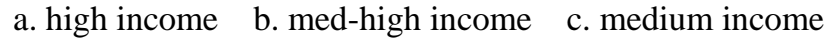

d. low-med income e. low income

11. Following are a number of statements. Circle all those which are correct about you.

a. I volunteer. I take care of my parents. c. I take care of my partner. d. I participate in synagogue activities. e. I am a salaried employee. I participate in courses/activity groups. g. I am an active political party member. h. I have other activities:

12. Following is a list of handicaps. Which apply to your parents? (please circle)

\begin{tabular}{ccccc}
\hline & handicap & non & partial & full \\
\hline 1 & walking & 1 & 2 & 3 \\
2 & sight & 1 & 2 & 3 \\
3 & hearing & 1 & 2 & 3 \\
\hline
\end{tabular}

13. When you need to make a decision regarding your parents, do you consult anyone? (please circle extent of consultation)

$\begin{array}{llllllll}\text { Consult } & 1 & 2 & 3 & 4 & 5 & \text { Do not consult at all }\end{array}$

14. To what degree is the following statement correct for you?

I prefer to keep my parents’ problems to myself. (please circle extent of truthfulness)

\begin{tabular}{lllllll}
\hline Very true & 1 & 2 & 3 & 4 & 5 & Not true at all \\
\hline
\end{tabular}

15. Following are a list of statements regarding the rights of and services for the Senior citizens. Please indicate if the statements are true or false to your knowledge.

\begin{tabular}{|c|c|c|c|c|}
\hline & Rights of and services for the elderly & true & false & I don't know \\
\hline 1 & $30 \%$ discount on residence property taxes. & 1 & 2 & 3 \\
\hline 2 & $\begin{array}{l}\text { Free consultation by social security regarding various subjects, such as: } \\
\text { finding occupation for leisure time, aid with social and personal matters. }\end{array}$ & 1 & 2 & 3 \\
\hline 3 & $\begin{array}{l}\text { 75\% discount on prescription medicines for recipients of } \\
\text { guaranteed minimal income pensions. }\end{array}$ & 1 & 2 & 3 \\
\hline 4 & $50 \%$ discount on will transcription fees when prepared by regional court registrar & 1 & 2 & 3 \\
\hline 5 & Disability pension may be used for laundering services & 1 & 2 & 3 \\
\hline
\end{tabular}




\begin{tabular}{|c|c|c|c|c|}
\hline 6 & $\begin{array}{l}\text { Information regarding rights and laws and legal counsel is provided } \\
\text { by the citizen consultancy service for a fee. }\end{array}$ & 1 & 2 & 3 \\
\hline 7 & $\begin{array}{l}\text { Residence in a retirement home for the ill is financed by } \\
\text { transferring the ownership of his/her home to the institution. }\end{array}$ & 1 & 2 & 3 \\
\hline 8 & $\begin{array}{l}\text { A senior citizen recipient of a guaranteed minimal } \\
\text { income pension is entitled to a } 100 \% \text { discount on property taxes. }\end{array}$ & 1 & 2 & 3 \\
\hline 9 & $\begin{array}{l}\text { A bedridden senior citizen is entitled to receive medical services, } \\
\text { such as, physiotherapy, in his/her home. }\end{array}$ & 1 & 2 & 3 \\
\hline 10 & $\begin{array}{l}\text { Only those who live off of social security pensions are entitled } \\
\text { to daily help when they are sick. }\end{array}$ & 1 & 2 & 3 \\
\hline 11 & Community centers have courses and activities for the senior citizens. & 1 & 2 & 3 \\
\hline 12 & $\begin{array}{l}\text { If a parent lives with a child he /her is not entitled to } \\
\text { free of charge treatment aid when sick. }\end{array}$ & 1 & 2 & 3 \\
\hline 13 & One cannot do volunteer work over the age of 78 & 1 & 2 & 3 \\
\hline 14 & Senior citizens are entitled to a $50 \%$ discount at the Habima and Cameri theaters. & 1 & 2 & 3 \\
\hline 15 & $\begin{array}{l}\text { All senior citizens over the age of } 80 \text { are entitled to receive } \\
\text { a guaranteed minimal income pension. }\end{array}$ & 1 & 2 & 3 \\
\hline 16 & The disability pension is transferred to a family bank account. & 1 & 2 & 3 \\
\hline 17 & $\begin{array}{l}\text { The disability pension is between } 100 \%-150 \% \text {, depending on } \\
\text { the necessary help and supervision required by the patient. }\end{array}$ & 1 & 2 & 3 \\
\hline 18 & $\begin{array}{l}\text { After hospitalization for a severe illness, one is entitled } \\
\text { to recovery days in a convalescent home. }\end{array}$ & 1 & 2 & 3 \\
\hline
\end{tabular}

16. Following are a number of information sources. To what extent do you use each?

\begin{tabular}{|c|c|c|c|c|c|c|}
\hline & Rights of and services for the elderly & Frequently & & & & Not at all \\
\hline 1 & $30 \%$ discount on residence property taxes. & 1 & 2 & 3 & 4 & 5 \\
\hline 2 & Neighbors & 1 & 2 & 3 & 4 & 5 \\
\hline 3 & Media, such as: newspapers, radio, television & 1 & 2 & 3 & 4 & 5 \\
\hline 4 & Children and grandchildren & 1 & 2 & 3 & 4 & 5 \\
\hline 5 & Specialists, such as: doctors, lawyers, HMO nurses, municipal social workers & 1 & 2 & 3 & 4 & 5 \\
\hline 6 & Social security consultants & 1 & 2 & 3 & 4 & 5 \\
\hline 7 & Citizen consultancy service & 1 & 2 & 3 & 4 & 5 \\
\hline 8 & Internet & 1 & 2 & 3 & 4 & 5 \\
\hline 9 & Reut-Eshel information center & 1 & 2 & 3 & 4 & 5 \\
\hline 10 & Other. Please specify & 1 & 2 & 3 & 4 & 5 \\
\hline
\end{tabular}

17. Following is a list of rights of and services entitled to by senior citizens. To what extent are you interested in receiving information regarding the following?

\begin{tabular}{lccccccc}
\hline & Services and Rights & Frequently & & \multicolumn{2}{c}{ Not at all } \\
\hline 1 & Property tax discounts & 1 & 2 & 3 & 4 & 5 \\
2 & Social security benefits & 1 & 2 & 3 & 4 & 5 \\
3 & Legal consultation regarding inheritance and wills & 1 & 2 & 3 & 4 & 5 \\
4 & Places that provide information services & 1 & 2 & 3 & 4 & 5 \\
5 & Rights and benefits of holocaust survivors & 1 & 2 & 3 & 4 & 5 \\
6 & Financing sources for residence in retirement home & 1 & 2 & 3 & 4 & 5 \\
\hline
\end{tabular}




\begin{tabular}{lcccccc}
\hline 7 & Leisure services & 1 & 2 & 3 & 4 & 5 \\
8 & $\begin{array}{c}\text { Special HMO services, such as: house calls and } \\
\text { convalescence following hospitalization } \\
\text { Other services/rights. Please specify }\end{array}$ & 1 & 2 & 3 & 4 & 5 \\
9 & 1 & 2 & 3 & 4 & 5 \\
\hline
\end{tabular}

18. Please indicate the language in which you prefer to receive information.

\begin{tabular}{cccccc}
\hline 1 & 2 & 3 & 4 & 5 & 6 \\
\hline \multirow{2}{*}{ Hebrew } & Russian & English & French & Yiddish & Other: \\
\hline
\end{tabular}

19. Please answer the following questions by circling the correct answer.

a. Do you want to receive the information in legal terms as appears in the statute book?

$\begin{array}{llllllll}\text { Very much so } & 1 & 2 & 3 & 4 & 5 & \text { Not at all }\end{array}$

b. Do you want to receive a summary of the information in simple terms, rather than as appears in the statute book?

$\begin{array}{llllllll}\text { Very much so } & 1 & 2 & 3 & 4 & 5 & \text { Not at all }\end{array}$

c. Would you like to receive the addresses and hours of service of the institutions that provide services?

$\begin{array}{lllllll}\text { Very much so } & 1 & 2 & 3 & 4 & 5 & \text { Not at all }\end{array}$

20. Following are a list of statements. To what extent are they true for you?

a. I need information to stay updated about my parents' entitlement to rights and services.

$\begin{array}{lllllll}\text { Very much so } & 1 & 2 & 3 & 4 & 5 & \text { Not at all }\end{array}$

b. I use information to solve my parents' daily problems.

$\begin{array}{llllllll}\text { Very much so } & 1 & 2 & 3 & 4 & 5 & \text { Not at all }\end{array}$

c. I use information to plan my parents' future.

$\begin{array}{lllllll}\text { Very much so } & 1 & 2 & 3 & 4 & 5 & \text { Not at all }\end{array}$

d. I use information to deal with the changes which occur in my parents' lives over the years.

$\begin{array}{lllllll}\text { Very much so } & 1 & 2 & 3 & 4 & 5 & \text { Not at all }\end{array}$

21. How necessary is it to have a person whose job is to provide information regarding laws and services for 40 -60 year olds.

Very much so

$4 \quad 5 \quad$ Not at all

22. Following is a list of possible ways to deliver information to you. To what degree would you prefer each possibility?

\begin{tabular}{ccccccc}
\hline & Means of delivering information & Very much & & Not at all \\
\hline 1 & Telephone & 1 & 2 & 3 & 4 & 5 \\
2 & Face to face discussion with information provider & 1 & 2 & 3 & 4 & 5 \\
3 & Fax & 1 & 2 & 3 & 4 & 5
\end{tabular}




\begin{tabular}{lcccccc}
\hline 4 & Mail & 1 & 2 & 3 & 4 & 5 \\
5 & Distribution in public places, such as: HMO and the municipality & 1 & 2 & 3 & 4 & 5 \\
6 & Home delivery by a volunteer & 1 & 2 & 3 & 4 & 5 \\
7 & Email & 1 & 2 & 3 & 4 & 5 \\
8 & Other. Please specify & 1 & 2 & 3 & 4 & 5 \\
\hline
\end{tabular}

23. To what degree are you interested in receiving information in each of the following formats?

\begin{tabular}{lcccccc}
\hline & Format & Very much & & \multicolumn{2}{c}{ Not at all } \\
1 & Pamphlets & 1 & 2 & 3 & 4 & 5 \\
2 & Tapes & 1 & 2 & 3 & 4 & 5 \\
3 & Internet sites & 1 & 2 & 3 & 4 & 5 \\
4 & Other. Please specify & 1 & 2 & 3 & 4 & 5 \\
5 & At the community center/public library & 1 & 2 & 3 & 4 & 5 \\
7 & At municipality & 1 & 2 & 3 & 4 & 5 \\
\hline
\end{tabular}


Scientific Research Publishing (SCIRP) is one of the largest Open Access journal publishers. It is currently publishing more than 200 open access, online, peer-reviewed journals covering a wide range of academic disciplines. SCIRP serves the worldwide academic communities and contributes to the progress and application of science with its publication.

Other selected journals from SCIRP are listed as below. Submit your manuscript to us via either submit@scirp.org or Online Submission Portal.
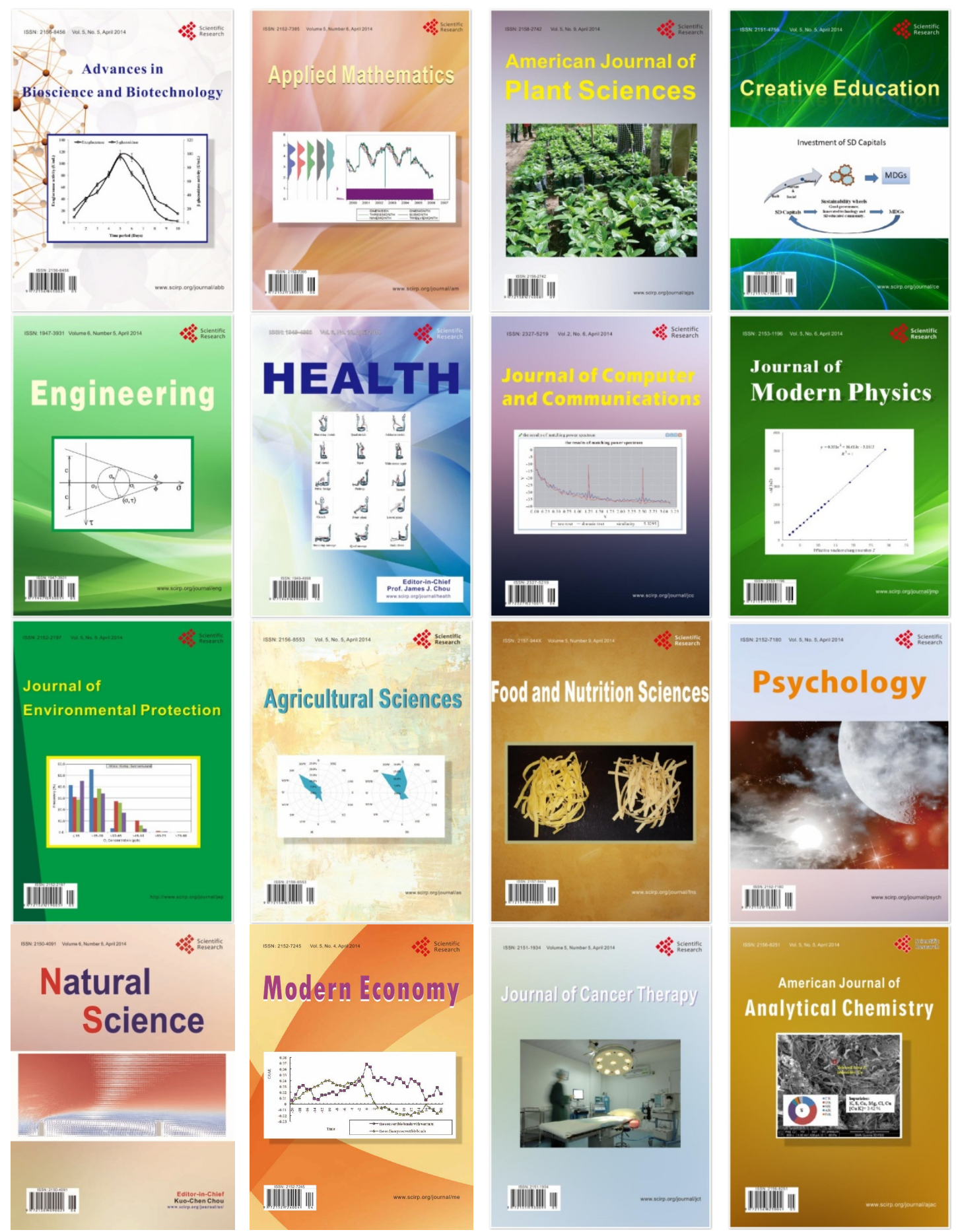